\title{
Re-framing student academic freedom: a capability perspective
}

\author{
Bruce Macfarlane
}

Published online: 14 September 2011

(C) The Author(s) 2011. This article is published with open access at Springerlink.com

\begin{abstract}
The scholarly debate about academic freedom focuses almost exclusively on the rights of academic faculty. Student academic freedom is rarely discussed and is normally confined to debates connected with the politicisation of the curriculum. Concerns about (student) freedom of speech reflect the dominant role of negative rights in the analysis of academic freedom representing 'threats' to academic freedom in terms of rights which may be taken away from a person rather than conferred on them. This paper draws on the distinction between negative and positive rights and the work of Sen (1999) to re-frame student academic freedom as capability. It is argued that capability deprivation has a negative impact on the extent to which students can exercise academic freedom in practice and that student capability can be enhanced through a liberal education that empowers rather than domesticates students.
\end{abstract}

Keywords Academic freedom $\cdot$ Students $\cdot$ Rights $\cdot$ Capability

\section{Introduction}

Academic freedom is one of the most enduring topics of scholarly debate and enquiry with a voluminous literature. Books, articles, special editions of journals and even campaigning organisations abound seeking to promote and protect the right of scholars to teach and enquire without fear of losing their jobs or being intimidated. It is a liberty given specifically to scholars the historical antecedents of which can be traced to the medieval European universities of the eleventh and twelfth centuries (Karran 2009). The contemporary relevance of academic freedom is reinforced through the activities of a variety of lobby groups and professional associations concerned with its protection and promotion such as the American Association of University Professors (AAUP), the Canadian

\section{B. Macfarlane $(\bowtie)$}

Faculty of Education, The University of Hong Kong,

Pokfulam Road, Pokfulam, Hong Kong SAR

e-mail: bmac@hku.hk 
Association of University Teachers, Scholars at Risk, Academics for Academic Freedom (AFAF) and the Council for Academic Freedom and Academic Standards (CAFAS).

Concerns with respect to tenure and freedom of expression of faculty are central to the functioning of academic life. But amid much of the contemporary debate about academic freedom the fact that academic freedom also applies to students has been long overlooked (Bissell 1969). Academic freedom is about the freedom of scholars; and students, not just faculty, are scholars too. They are members of a community of scholars (Monypenny 1963). This is an integral part of the Humboldtian tradition, where scholarship is defined in terms of the pursuit of knowledge and understanding as a common goal, necessarily involving both students and teachers (Karran 2009). Both are, in essence, learners.

Much of the literature, however, reinforces a one-dimensional understanding of academic freedom by making only fleeting reference to students or sometimes overlooking their importance altogether. Conrad Russell's book Academic Freedom (1993) is an example of this apparent myopia. In the UK, a particularly self-regarding version of academic freedom has been reinforced by the protection given to academics, not students, by the Education Reform Act (1988). This states that the jobs of faculty must not be jeopardised by them putting 'forward new ideas and controversial and unpopular opinions' (section 202(2)). There is no mention of students, just faculty. This has the effect of excluding students as members of the academic community with a similar entitlement to academic freedom. It overlooks the importance of developing students with the capacity to function as informed and critical members of civic society.

Indeed, sometimes student academic freedom is treated as merely the by-product of the protection of the freedom of academics. The argument here is that it is only when faculty are free that they are in the position to expose students to the range of ideas and arguments that will, in turn, help them to find their own voice. While the 1915 AAUP statement on academic freedom made reference to student academic freedom, it took it as read that the focus of the report was the academic freedom of the teacher (AAUP 1915). Where students were mentioned in the statement it is by reference to how their freedom is inhibited or facilitated by that of the teacher.

Hence, the claim to student academic freedom has rarely been presented 'with either clarity, consistency or adequacy' (Magsino 1978: 48). This is partly due to the fact that although students are formally members of a community of scholars they essentially occupy a position of dependence in that they are subject to the authority of their teachers and institutions in respect to grading and the certification of their achievement through the award of degrees (Monypenny 1963). Although rarely stated in a contemporary context, an implicit, but patronising, assumption is that, as novices or scholars in training, students do not possess the knowledge necessary to make sufficiently informed judgements (Horn 1999). Where student academic freedom is acknowledged this tends to assume an exclusively negative rights perspective focusing on the extent to which students are effectively denied the opportunity to develop critical faculties and exercise freedom of expression as a result of faculty proselytising their own political and radical opinions.

This article will seek to elaborate the claim to student academic freedom more broadly by identifying a number of ways in which it may be enhanced drawing on the distinction between positive and negative rights and applying Sen's (1999) concept of 'capability'. Student academic freedom is important both as a right to full and free expression and as a means by which learners can experience a genuinely 'higher' education that enables them to become critical thinkers. The article will also argue that student academic freedom requires active protection and promotion in the face of passive and proactive threats. 


\section{The politicisation debate}

On the occasions where attention has been focused on student academic freedom discussion normally centres on the so-called politicisation of the curriculum. The assumption here is that 'being "free to learn" means being free from indoctrination' (Pavela 2005: xx). In the United States the debate about student academic freedom has focused almost exclusively on the contention of neo-conservative lobbyists and critics that students are being politicised by radical university teachers. This cause is championed by David Horowitz and his Students for Academic Freedom campaign, which argues that a leftleaning professoriate is trying to radicalise university students by indoctrinating them with a set of 'liberal' values. The events of 9/11 have heightened concerns about terrorism and national security on both sides of the Atlantic leading to a re-opening of the debate about freedom of speech and extremism on campus (Altbach 2009). It is claimed by Horowitz's campaigning organisation, Students for Academic Freedom, that there is a lack of 'balance' in the teaching of controversial subjects and this creates a classroom atmosphere which is intolerant to students with dissenting views. The effect of this process, according to Horowitz, is that students are prevented from developing their own independent thinking or might, to some extent, self-censor. The Student Bill of Rights, produced by Horowitz, focuses exclusively on concerns with respect to 'indoctrination' of students as a violation of their freedoms and the potential impact of related issues, such as unfair assessment, which might affect a student who expresses opinions contrary to those held by their professor.

Despite the concerns raised by Horowitz, the 1915 statement on academic freedom issued by the AAUP does include a clear instruction that students in their formative years of undergraduate education should be safeguarded from unbalanced approaches:

The teacher ought also to be especially on his [sic] guard against taking unfair advantage of the student's immaturity by indoctrinating him with the teacher's own opinions before the student has had an opportunity fairly to examine other opinions upon the matters in question, and before he has sufficient knowledge and ripeness of judgment to be entitled to form any definitive opinion of his own.

(AAUP 1915: 298-299)

Horowitz' campaign though has led to the AAUP issuing a response entitled Freedom in the Classroom (AAUP 2007). AAUPs 2007 statement affirms that it is a teachers' right to test out their opinion and beliefs on controversial issues in the classroom without regard to the extent to which the views expressed represent opinions based on untested assertions. Here, a counter-argument is that faculty should distinguish between audiences. Students (especially undergraduates) should be distinguished from professional or disciplinary peers. In other words, the testing out of controversial or new ideas should be directed at peers, and in the context of a scholastic debate, with equals. In an earlier incarnation of the controversy about the politicisation of the curriculum, Max Weber distinguished between opportunities to profess views in the classroom and to peers and talked of the 'obligations of self-restraint' on the university teacher (Weber 1973a: 22). Explaining this view, he argued that:

Like everyone else, the professor has other opportunities for the propagation of his ideals...in the press, in public meetings, in associations, in essays, in every avenue which is open to every other citizen, he can and should do what his God or daemon demands' (Weber 1973b: 50). 
The Association of American Colleges and Universities (AACU) has also issued a defensive statement about student academic freedom in response to Horowitz's campaign (AACU 2006). In common with that issued by the AAUP, it focuses on discussing student academic freedom almost exclusively in terms of the politicisation debate.

\section{Rights and capability deprivation}

Hence the debate focuses on the threat to student freedom of thought and expression caused by 'unbalanced' teaching that indoctrinates rather than educates. Regardless of the extent to which this charge may be true, student academic freedom is a more complex and multi-dimensional issue than concerns about learner politicisation might suggest. In seeking to understand the different dimensions of student academic freedom, it is pertinent to apply the concept of negative and positive rights and Sen's (1999) concept of capability.

Negative rights are ones which are assumed to exist or be defined as 'inalienable' such as the right to life or the right to free speech. People should enjoy certain rights 'without interference from other persons' (Berlin 1969: 122). To lose such a right would imply that someone or something (e.g the state) is trying to take them away from somebody by taking their life, shackling their movements or preventing them from speaking. This is the usual way in which rights are understood and expressions of human rights in legal documents, such as the US Bill of Rights, tend to mainly contain a list of negative rights. Clearly it is important to protect a student's freedom of speech from a negative rights perspective. It should not be threatened or taken away. This is the concern of those that claim politicisation since it might lead students to self-censor their views.

In contrast with negative rights, positive rights are those to something such as education, employment or a minimum wage and are associated with a social justice agenda. If people do not have capabilities, often associated with those conferred by education such as literacy, they are not able to properly exercise freedom in any real sense. In the context of improving the quality of life of those living in the developing world, this is the argument made by Sen (1999). According to Sen, people are not always able to exercise freedoms because they lack the functional capability (or 'substantive' freedom) to do so. For example, if someone is poorly educated, or perhaps illiterate, they will never really be able to fully exercise their political freedoms. Freedom is adversely affected by 'capability deprivation' (Sen 1999: 20) as a result.

Defining student academic freedom as freedom of speech denotes a negative rights perspective as it does not take account of the capabilities that are required that underpin the exercise of this freedom. There are several different dimensions to student academic freedom that rarely get any attention which might be understood more generally as positive rights or capabilities. Academic freedom, in the German tradition, may be understood in terms of the freedom to teach (lehrfreiheit) and the freedom of students to learn (lernfreiheit). Much attention has been focused on lehrfreiheit and very little on the allied concept of lernfreiheit according to which students should be free to pursue the course of their choice at whichever institution of higher education they might choose. Yet, there are elements of the lernfreiheit tradition which remain important if we are to continue to take seriously and promote, rather than 'protect' in a negative rights tradition, student academic freedom. 


\section{Reframing student academic freedom}

Reframing student academic freedom in terms of positive rights is important since it implies a proactive stance. A passive stance is one where it is assumed that no action is required to protect student academic freedom unless a 'threat' emerges, such as an aggressively indoctrinating teacher. However, more positively student academic freedom can be re-framed in terms of positive rights implying a proactive approach in seeking to develop the independence of students as thinkers and learners to their fullest extent. Assuming they support academic freedom, this means that universities, and their faculty, have an obligation to promote student capability. This, ultimately, is the most effective means of ensuring student academic freedom is protected.

How can student academic freedom be promoted through a capability approach? At root, capability depends on education and this presupposes the right to gain access to a university education. This implies campaigning for access to higher education as an affordable right for all, regardless of formal and informal historical restrictions such as religion and social class. Article 26 of the 1948 Universal Declaration of Human Rights (United Nations 2009) states that everyone has the right to an education and that higher education should be accessible on the basis of merit. The global enrolment rate for higher education rose from $18 \%$ in 1999 to $25 \%$ by 2006 partly as a result of the expansion of the university system in India and China (UIS 2008). Yet, access to higher education is denied to people in a number of national contexts, such as Malaysia, where racial policies discriminate against Chinese and Indian members of the population who are not defined as indigenous. However, the opportunity to benefit from a higher education is more generally denied in many economically prosperous nations on the basis of its inaccessibility due to cost and other socio-economic hurdles. France is unusual in this context in providing students with a legal entitlement to gain access to their local university without any pre-selection process if they have passed the baccalaureate.

It is sometimes forgotten that universities have a long history of serving the church and the state which has restricted the right to access to a higher education. Whilst the cost of a university education has historically excluded large swathes of the population on the basis of their social class, barriers to entry on the basis of gender, race and religion have also been a significant break on social progress. While the struggles of women and the black population in the United States and South Africa are perhaps better known, one of the more overlooked aspects of this history was exclusion on the basis of religion in a number of countries including Britain.

The ancient British universities, with the exception of Edinburgh, were all church established (Robinson 2005). In England, non-conformists (or 'protestant dissenters') were unable to gain access to a university education until the founding of University College London in 1826. It was not until the passing of the University Tests Act in 1871 that the so called religious test was abolished in England. The restriction remained in force in Scotland until 1889. The aim of Oxford and Cambridge colleges, even during the nineteenth century, was essentially to train young men 'to serve God in Church and State' (Twaddle 1966: 45). Weber's argument for so-called value-free science and for university professors to eschew political opinions when teaching students stems from the university politics which prevailed during the early part of the twentieth century (Josephson 2004). At this time, the universities in Germany were tightly controlled by the state and the influence of the Church was still substantial in relation to professorial appointments.

The right to a higher education from a negative rights perspective has been hard won. However, the notion of education as a positive right is perhaps less well understood and 
associated principally with compulsory age schooling. It was not until the latter half of the twentieth century that university systems in most developed countries started to 'massify'. Elite systems of higher education, such as those in the UK or Australia, have been transformed into mass and now nearly universal systems in Trow's terms (Trow 1973). Participation rates in higher education have risen rapidly in a large number of developed and developing economies since the late twentieth century. Globally the proportion of young people going on to tertiary education has risen from under one in five in 2000 to more than one in four in 2007 with women now outnumbering men (UNESCO 2009). There are though stark regional differences with just $6 \%$ of Africans entering tertiary education compared with more than $70 \%$ in North America and Europe (UNESCO 2009). Even in developed country contexts barriers to access to higher education represent a threat to students gaining the opportunity to develop their full capabilities. Hence, it is important to recognise that mass access to higher education is a comparatively recent phenomenon. Critically, access to a higher education is now being viewed as a right rather than a privilege.

Student academic freedom further depends on a university curriculum that enhances the capability of students to develop as independent and critical thinkers. It has long been argued that students have a right to a general or liberal education in the shape of a university curriculum which is sufficiently broad to enable someone to become an independent and critical thinker as well as, perhaps, play an informed role as a citizen. The case for the contemporary relevance of a liberal undergraduate curriculum has been recently made afresh by Alasdair MacIntyre. Drawing on Newman, MacIntyre (2009) argues that undergraduate education needs to be seen as something that has its own ends which are distinctive from, and not simply a prologue for, graduate or professional education. He blames many of the twentieth and early twenty-first century conflicts, such as Vietnam and American policies toward Iran, on 'distinguished graduates of some of the most distinguished universities in the world' (p. 361) Recommending Newman's view of a broad and liberal undergraduate education, but for the many rather than the few, he contends that these distinguished graduates have made poor decisions due to 'an inadequate general education' (p. 361).

Another argument is that the pace of change in the modern world makes specific skill and knowledge sets rapidly outmoded. Only a broad, liberal education, that develops human qualities and dispositions rather than 'generic skills', can adequately prepare students for an essentially unknown future (Barnett 2004). In other words, a broad curriculum is more likely to 'future-proof' graduates. Conscientious faculty in vocational areas of the curriculum have long understood the importance of a curriculum which seeks to strike a balance between teaching time-sensitive employment-related skills and a broader theoretical and contextual knowledge base which is future oriented. Those who teach visual communication courses, for example, are conscious of the risks of focusing too heavily on software skills. The rapid pace of change in their industry means that what is current now may soon be redundant (Marshall and Meachem 2005).

Thinking of the curriculum in this way would imply the provision of sufficient opportunities for students to add breadth to their specialist studies via elective courses. This does not mean that conventional course-based degrees devoid of electives cannot produce breadth of learning but that general education via electives can add a further dimension to the development of students. In its original sense, lernfreiheit implied that students should be free to roam between institutions of higher education, pursue whichever courses took their fancy, attend as they wished and not to be subjected to any form of test except for a final examination (Mumford Jones 1960). Modern higher education is very far from this 
idealised portrait of the student as an unencumbered travelling scholar. Many courses in higher education are highly specialised and offer students tightly restricted opportunities to take electives outside a relatively narrowly defined curriculum. Modern courses have been packaged into 'modules' or 'units' which allow few opportunities for students to develop their critical thinking or evaluative skills.

In a European context, the Bologna agreement is playing a critical role in harmonising but, at the same time, narrowing the scope and depth of degree study particularly at undergraduate level. This has forced the re-configuration of four-year undergraduate degree programmes into the three-year model and has had a profound effect on countries such as Germany, Austria and Portugal where the four-year model has strong historical roots. A Europe-wide report reveals that while the vast majority of institutions have now implemented the new Bologna degree structure it 'has not led to meaningful curricular renewal, but rather to compressed Bachelor degrees that leave little flexibility for students' (Sursock and Smidt 2010: 7). This adversely affects programmes where student mobility or internships are important features such as in languages or business. Hence, the reality is that students have less choice. The three-year bachelor degree is also squeezing out elements of the curriculum which might be characterised as more 'liberal' in nature. In many European countries students have traditionally received a more broadly based form of cultural development as a citizen, or Bildung, via a liberal education. In England the undergraduate curriculum has been configured on a narrower basis for many years. Indeed, as part of an economically driven efficiency model, the British government now sees the development of even shorter two-year degrees as integral to the future of higher education (Department of Business, Innovation and Skills 2009). An isolated example of the reverse of this trend is the introduction of a 4 year undergraduate degree programme in Hong Kong in 2012. Here, an experiment is underway to re-structure the curriculum to increase the emphasis on the liberal arts, languages, ethics and philosophy. Students will also be allowed to delay their choice of a 'major' until the end of their first year allowing them more time to reflect and mature.

A liberal education that enhances student academic freedom is not about the inculcation of particular sets of attitudes or values. Here, a distinction needs to be made between domestication and empowerment. Domestication involves seeking to implant specific sets of civic imperatives such as developing students as 'global citizens' or demonstrating that they 'care about the environment' and so on. By contrast, a liberal education that empowers students is centred on students developing critical thinking skills and their own voice rather than one which is aligned with inculcating conventional values and politically correct mantras. A significant challenge in Hong Kong is to ensure that general education within the undergraduate curriculum becomes a tool for empowerment as opposed to domestication.

The scaling back of the scope and ambition of the doctoral thesis is a further cause for concern. There is increasing evidence that doctoral theses have been circumscribed by pressure from research councils for their timely completion. In 1990 less than three quarters of PhDs funded by the UK Economic and Social Research Council were completed on time. By 2002, tighter rules led to this figure rising to four fifths (Economic and Social Research Council 2007). While this trend might appear to indicate greater efficiency, it also means that more risky and ambitious projects are less likely to be given the go-ahead. This restricts the sense in which doctoral education represents an intellectual challenge for able students. Taught elements and compulsory training have been increasingly added to doctoral programmes. In the space of 3 years, between 2007 and 2010 , it is reported that the number of institutions offering additional taught elements has 
increased from 49 to $72 \%$ (Sursock and Smidt 2010). The scaling back of the doctorate as a major intellectual project raises more fundamental questions about its purpose which is increasingly being cast in terms of preparation for employment rather than an academic career.

While AACU's statement about academic freedom focuses on the politicisation issue (AACU 2006), there is a recognition of the importance of a liberal education in helping students to develop the skills of critical thinking and enquiry which enable them to develop their own perspectives on issues that face modern society. Hence, there is an implicit understanding here that liberal education is a key positive right that facilitates student academic freedom. The modern curriculum of higher education though is tending to restrict the extent to which students are able to develop a broadly-based understanding of knowledge which would make them more informed as citizens and, hence, able to exercise their 'negative' rights as fully as they might do (e.g freedom of speech).

\section{Student academic freedom: threats and responses}

While fair access to higher education and a liberal curriculum make a positive contribution to the development of student academic freedom, there are forces which are undermining student capability rather than enhancing it. Examples include the development of attendance policies, the theft of student intellectual property and the domestication of the student 'voice'. Here, it is important to develop responses to these threats to student academic freedom.

Attendance policies

A range of factors are leading universities to develop policies with respect to student attendance and 'engagement' in learning more generally. These include immigration rules directed at international students, concerns about student progression and non-completion, the increasing use of the internet and virtual learning environments and a more general 'moral panic' with respect to the extent to which students are engaging in 'deep' as opposed to 'surface' learning. It is clear that, in part, this phenomenon is also linked to an increasing sense of isolation among students in a mass higher education environment and the fact that being at university is only one element of their lifestyle, particularly for those who are in employment either part or full-time. At Oxford Brookes Business School in the UK, for example, $25 \%$ of first year undergraduates have never had a conversation with a faculty member outside of class while $43 \%$ may have 'only had one or two interactions in the course of an academic year (Oxford Brookes University 2009: 1).

At worst these attendance and engagement policies consist of little more than an attendance register and a short-sighted refusal to consider the underlying reasons for student disengagement, including poor or inadequate teaching. More enlightened policies recognise the complexity of the issue and that poor teaching and timetabling of classes which take little account of student needs contribute to a lack of engagement. Some universities are taking a more hard-line attitude toward this issue by seeking to enforce policies on student class attendance.

The emerging policy of UK universities in this area rarely takes account of the counterargument that a compulsory attendance requirement is inappropriate in the context of a higher education. Firstly, higher education is a post-compulsory phase of education and students are, in most national systems such as the UK, legal adults. They are at university 
through choice rather than compulsion, most are mature and work full or part-time. Moreover, students increasingly pay or defer payment for the cost of their own university studies via tuition fees as a result of which they are increasingly being portrayed, and act, as 'customers'. Here, it is unclear what reciprocal rights students derive from the imposition of an attendance requirement. Furthermore, poor attendance at lectures and seminars is nothing new in higher education. Students traditionally 'read' for a university degree and chose what to attend according to need and interest. What is new is simply the expectation that students should attend and engage. Finally, while it is common for universities to have attendance regulations, historically they have rarely been enforced in practice.

Attendance and engagement policies are part of a culture which treats university students as children rather than adults. This 'infantalisation' (Furedi 2003) removes choice and judgement about the value of personal time and how this is best spent. This curiously contradicts the oft espoused commitment that students should become independent learners. It also hollows out what it means to be a higher education student and reduces it down to a compliance-based denominator. Gaining academic credit for attendance is part of a growing pattern of presenteeism in higher education. Presenteeism is increasingly apparent in assessment design through the use of contribution grades, particularly in a North American context, and group assessment which has resulted from the massification of higher education. Group assessment practices are often underpinned by a genuine concern to improve the quality of the student learning experience but can be open to abuse as a means to cope with assessment loads. Most group assessment allocates a single grade to the group without account being taken of individual contributions. Attendance at group oral presentations is necessary for students to demonstrate that they 'deserve' the grade regardless of how little they may have contributed. Another example of this trend is the use of online tracking systems which can gauge how often a student contributes to an online forum as part of a discussion. While the number of contributions may be recorded electronically this pays little regard to the quality of such interventions no matter how well-informed they might be.

Teaching that closely links assessment and student learning through integrated forms of assessment provide a more positive alternative to attendance policies. Here, rather than focusing on the negation of student independence, the emphasis is on motivating students to participate fully in the learning process rather than treating assessment as a 'bolt on' activity. This involves, in part, the development in students of 'connoisseurship' (Sadler 1989) by developing instructional systems that enable them to acquire the acumen and store of tactics to identify what high quality academic work is and modify their own work accordingly. If students are going to be able to improve and grow as learners they need to develop this capacity for self-evaluation. A number of writers and researchers have built on Sadler's work by suggesting ways that the classroom can be developed as a community of co-learners such as via the use of blogs (Churchill 2009). Sadler's concept of connoisseurship speaks directly to the treatment of students as members of the academic community giving them access to the insider knowledge that they are often denied in conventional approaches to learning and teaching. In Sadler's terms it is about inducting students into the 'guild' of what it means to be an academic, sharing this expert knowledge and empowering them in the process. Engaging students in this way is about enabling them to develop their full capacity as learners. This contrasts with requirements to keep an attendance register as a control mechanism. Inspiring teaching which inducts students into guild knowledge largely negates the need to treat university students as children. 
The theft of intellectual property

A student, as a free scholar rather than an employee of the university, should be able to retain rights to their own intellectual property. Yet, students face two threats in safeguarding their own intellectual property and in the restriction on their freedom which results. The first of these is the formal introduction in recent years of university policies on intellectual property rights (IPR) which seek to exploit the commercial potential of inventions, copyright and patents. These policies are principally aimed at the research and innovation of academic faculty who are employees of the university. These policies normally assign IPR to the university where research or innovation with a commercial value has been generated in the normal course of employment. While the circumstances in which creativity takes place, and the extent to which academic faculty should share in commercial gains, is a source of argument, the assertion of the employer's right to benefit has a legal foundation.

It is notable, though, that a large number of universities have sought to apply a similar policy in circumstances where a student generates intellectual property of some kind. This is applied to students at all levels, including undergraduates, although it is more likely to affect a doctoral student engaged in original research. Yet, whilst faculty are employees of a university, students are not, even though graduate students frequently participate in teaching activities. Whilst students may draw to some extent on the resources of the institution in the course of their creative efforts and work in some cases with academic faculty, the assignment of their IPR to the university has a debatable legal foundation (Patel 1996). It is also dubious from a moral standpoint and acts as a further threat to student academic freedom. University policies on intellectual property rights often treat students in the same restrictive way as academic faculty even though they are clearly not employees such as that of the University of Leeds. Some universities, such as the University of Bristol, have what they describe as a 'fair share' system of dealing with IPR but still treat students in much the same way as they do a member of faculty by expecting the institution to benefit from commercial exploitation even though a student is not an employee.

This theft of student intellectual property also occurs in other less explicit or formal ways through tutors and lecturers drawing on the scholarship of students without credit. Such practices are rife in the world of doctoral education where there is a long, and undistinguished history of doctoral students discovering that their original scholarship subsequently appears in the publications of their supervisor without sufficient, or sometimes any, authorial credit. A frequent practice is so-called 'gift' or 'gratuitous' authorship where individuals who have not contributed to a study are named as a co-author. Invariably this occurs where senior faculty appear as co-authors on papers researched and written by research students (Lazar 2004). This practice mirrors what is sometimes termed 'organisational plagiarism' in a commercial context where a more senior manager takes credit for the work of a junior colleague. Here, the intellectual property of students can be subtly re-assigned to faculty who appear as the first (or last) named author of research papers based on their student's original scholarship. Some academic faculty perceive such practices as legitimate owing to the fact that the student's research has resulted from funding which they (i.e the faculty member) generated (Macfarlane and Saitoh 2009).

This particular threat to student academic freedom may be addressed through greater attention being given to authorship policies. Institutions have focused strongly on developing research ethics policies defined predominantly in terms of principles derived from the biosciences with a stress on the rights of human research subjects (Macfarlane 2009). However, these policies less commonly address authorial credit and the exploitation of student intellectual property. Faculty members have more knowledge and power than 
students and need to take ethical responsibility for the fair allocation of authorial credit where collaborative research takes place (Welfare and Sackett 2010). A number of scholarly and professional bodies do issue ethical guidelines for the recognition of student contributions (e.g American Educational Research Association, American Psychological Association) and the Vancouver protocol (ICMJE 2008) sets out an internationally recognised standard. While there is limited consensus with respect to authorship credit among faculty and students (Welfare and Sackett 2010), the Vancouver protocol is clear that an author can only be someone who contributes substantially to the generation and interpretation of data, drafts the article or revises it critically and gives final permission for it to be published (ICMJE 2008). Authorial credit is related closely with the treatment of students as members of the academic community with equal rights, if not equal status. Addressing this issue in a positive way would symbolise a commitment to enhancing the rights of students as scholars.

The domestication of the student voice

Student radicalism and activism is sometimes regarded as a unique feature of the student movement of the 1960s. The evidence though shows that students have long come into conflict with both their institutions and the state in seeking to exercise freedom of association and expression (Horn 1999). Even in the nineteenth century this included organising student (political) societies, publishing newspapers critical of the institution, and inviting controversial speakers to the campus.

Since the student radicalism of the 1960s however, institutions have sought to increasingly domesticate the 'student voice' for the benefit of the reputational status of the university. This is connected closely with the growth of a quality assurance culture reliant on student evaluation of teaching, a feature of modern university life which often attracts criticism as a potential threat to the academic freedom of faculty. Here, the use of such data in making tenure decisions is sometimes alleged to result in students knowingly abusing their evaluative role. In a contemporary context, student evaluation of teaching plays an increasingly important role in higher education in determining the reputation of institutions via the assessment of performance data. This is drawn on both by public funding bodies and students and parents looking to make comparisons between institutions. Universities are keen to use such data as a marketing tool where results are favourable as a critical part of reputation management. However, attenuated concern for reputation has led to coercive attempts to domesticate, and sometimes manipulate, student evaluation particularly where these feed into comparison with competitor institutions via 'league tables' (Kenber and Matthew 2010).

The 'student voice' has become the clarion call of political correctness in the modern university. Yet, students are increasingly being assigned a role as part of the quality assurance apparatus as student 'representatives' in course staff-student committees or in other internal monitoring and review processes. This is about the domestication of the 'student voice' and is illustrated by the often tokenistic inclusion of students in review processes. This involvement is used as a marketing tool to convince external agencies, such as the UK Quality Assurance Agency for higher education, that academic standards are robust within the institution.

In the UK, for example, the National Student Survey has become an increasingly high profile mechanism for the comparison of the quality of higher education institutions since its inception in 2005. A number of well-publicised incidents have demonstrated that universities have sought to implicitly and sometimes explicitly encourage students to overscore perceptions of the quality of their educational experience. The concern that a low 
response rate will exaggerate the influence of a small number of disgruntled individuals has led institutions to pressurise students to participate via a series of email reminders and further requests by telephone or text message. Heads of academic departments are implored to get their students to 'reflect positively' on their experiences at university. Other universities have gone further with staff members allegedly seeking to persuade students to give artificially high scores to boost the relative 'value' of their degree. Accusations that students are being pressurised exists not only in cyberspace. In 2010, the English higher education funding council reported complaints about eight universities covering the period 2008-2010 (Hutchison 2010). The most high profile of these allegations concerned Kingston University. In 2008, students at the University recorded a member of faculty unambiguously telling them to artificially inflate their ratings as the consequent ranking of the institution in the league table would impact on their employment prospects (Mostrous 2008).

These, and other, incidents have come to light largely as a result of the so-called digital democracy. Every individual is now a media channel and student blogs and social networking sites abound. Universities, acting as corporate rather than educational entities, have reacted defensively to the emergence of social networking sites as a popular means of giving voice to student concerns. Unlike student evaluation questionnaires which universities develop, analyse and present, they are unable to control this more free-form of student evaluation. There are also more formal and organised online sources for the evaluation of university teaching such as 'Ratemyprofessors.com' which have grown in importance in recent years (Otto et al. 2008). Universities often perceive these more informal and less controlled forms of evaluation as a threat to institutional reputation and tend to react defensively to criticisms posted outside the formal quality assurance apparatus of the university.

However, it is important to draw a distinction between student evaluation data collected by university authorities at an institutional level and that collected at the more local level by individual academics. While the former is likely to be quantitative and analyzed with a view to promoting the university's reputation, the latter is more likely to be more informally framed and often qualitative in nature resulting from discussions, focus groups and written comments. Here, it is important that the organisation of institutional level evaluation does not squeeze out the collection of informal, local but often more authentic evaluation feedback from students. Part of a more empowering approach involves allowing students to design and take central responsibility for evaluation rather than subjecting learners to standardised instruments (Giles et al. 2004).

\section{Conclusion}

Student academic freedom has been used as a political agenda by those who regard the university as a hotbed of academic radicalism. This has skewed the debate and resulted in the neglect of a broader set of issues which are adversely affecting the negative and positive freedoms of students. Reframing student academic freedom as capability provides an active rather than passive interpretation of the responsibilities of universities and professors. Arguably, developing students as critical thinkers is the transcendent professional value of university educators (Barnett 1990). This can be achieved through a curriculum that places an emphasis on the development of students as independent, critical thinkers. This needs to be understood as a liberal education for empowerment rather than one which inculcates students with a politically correct sets of values. Moreover, faculty members need to be alert to ways in which student academic freedom is being threatened through 
trends such as attendance requirements that erode student capability to make judgements over the use of their own time, and in the assessment of their educational experiences in narrowly prescribed ways which furnish information to bolster institutional reputation rather than self-evaluation. Here, faculty can counter such trends through continuing to encourage informal and student-led forms of evaluation assessment and integrating assessment with student learning and the development of connoisseurship.

It is important to re-conceptualise what we understand by student freedom. Much of this is about students being allowed or empowered to make their own decisions about their study environment and being unshackled from assumptions about their level of maturity. Several of the threats to student academic freedom outlined in this paper have tended to attract attention as undermining academic standards. Yet, the most significant consequence of a diminished education is to deprive students of the capability to exercise their freedoms in a meaningful way.

Open Access This article is distributed under the terms of the Creative Commons Attribution Noncommercial License which permits any noncommercial use, distribution, and reproduction in any medium, provided the original author(s) and source are credited.

\section{References}

Altbach, P. (2009). Academic freedom: A realistic appraisal. International Higher Education, 57, $2-5$.

American Association of University Professors (AAUP). (1915). Declaration of principles on academic freedom and academic tenure. http://www.aaup.org/AAUP/pubsres/policydocs/contents/1915.htm? $\mathrm{PF}=1$. Accessed March 13, 2010.

American Association of University Professors (AAUP). (2007). Freedom in the classroom. http://www. aaup.org/AAUP/comm/rep/A/class.htm. Accessed April 14, 2010.

Association of American Colleges and Universities (AACU). (2006). Academic freedom and educational responsibility. http://www.aacu.org/about/statements/documents/academicFreedom.pdf. Accessed April $12,2010$.

Barnett, R. (1990). The idea of higher education. Buckingham: Society for Research into Higher Education/ Open University Press.

Barnett, R. (2004). Learning for an unknown future. Higher Education Research and Development, 23(3), 247-260.

Berlin, I. (1969). Four essays on liberty. Oxford: Oxford University Press.

Bissell, C. (1969). Academic freedom: The student version. Queen's Quarterly, 76(2), 171-184.

Churchill, D. (2009). Educational applications of Web 2.0: Using blogs to support teaching and learning. British Journal of Educational Technology, 40(1), 179-183.

Department of Business, Innovation and Skills. (2009). Higher ambitions: The future of universities in a knowledge economy. London: The Department of Business, Innovation and Skills.

Economic and Social Research Council. (2007). Annual reports and accounts, 2006-2007. London: The Stationery Office.

Furedi, F. (2003). Therapy culture: Cultivating vulnerability in an uncertain age. London: Routledge.

Giles, A., Martin, S., Bryce, D., \& Hendry, G. (2004). Students as partners in evaluation: Student and teacher perspectives. Assessment and Evaluation in Higher Education, 29(6), 681-685.

Horn, M. (1999). Students and academic freedom in Canada. Historical Studies in Education, 11(1), 1-32.

Hutchison, P. (2010). Universities accused of pressuring students over satisfaction survey. The Daily Telegraph, 27 April.

International Committee of Medical Journal Editors (ICMJE). (2008).Uniform requirements for manuscripts submitted to biomedical journals: writing and editing for biomedical publication. The Vancouver Protocol.

Josephson, P. (2004). Lehrfreiheit, Lernfreiheit, Wertfreiheit: Max Weber and the University Teachers' congress in Jena 1908. Max Weber Studies, 4(2), 201-219.

Karran, T. (2009). Academic freedom: In justification of a universal ideal. Studies in Higher Education, 34(3), 263-283. 
Kenber, B., \& Matthew, T. M. (2010). Universities 'pressured students to inflate league table'. http://www. guardian.co.uk/global/2010/apr/26/universities-student-survey-rankings-investigation. Accessed March 5, 2011.

Lazar, R. (2004). Up for grabs-Authors are a dime a dozen: The problem of multiple authors. Acta Paediatrica, 93, 589-591.

Macfarlane, B. (2009). Researching with integrity: The ethics of academic enquiry. New York and London: Routledge.

Macfarlane, B., \& Saitoh, Y. (2009). Research ethics in Japanese higher education: Faculty attitudes and cultural mediation. Journal of Academic Ethics, 6(3), 181-195.

MacIntyre, A. (2009). The very idea of a university: Aristotle, Newman, and us. British Journal of Educational Studies, 57(4), 347-362.

Magsino, R. F. (1978). Student academic freedom and the changing student/university relationship. In K. Strike \& K. A. Egan (Eds.), Ethics and educational policy (pp. 36-57). Routledge and Kegan Paul: London.

Marshall, L., \& Meachem, L. (2005). Widening access, narrowing curriculum: is the expectation of software training changing the culture within visual communications' higher education? In Published proceedings for 5th International Conference on Educational Technology in Cultural Context (ICALT 2005), Kaohsiung, Taiwan, July. In Proceedings: The 5th IEEE International Conference on Advanced Learning Technologies, pp. 1052-1056.

Monypenny, P. (1963). Toward a standard for student academic freedom. Law and Contemporary Problems, 28(3), 625-635.

Mostrous, A. (2008). Kingston University students told to lie to boost college's rank in government poll, TimesOnline, 14 May. http://www.timesonline.co.uk/tol/news/uk/article3924417.ece.

Mumford Jones, H. (1960). The American concept of academic freedom. AAUP Bulletin, 46(1), 66-72.

Otto, J., Sanford, D., \& Ross, D. (2008). Does ratemyprofessor.com really rate my professor? Assessment and Evaluation in Higher Education, 33(4), 355-368.

Oxford Brookes University. (2009). Student attendance and engagement. https://mw.brookes.ac.uk/display/ CDIs/Business+School+Undergraduate+Programe+Renewal+January+2009. Accessed May 4, 2010.

Patel, S. H. (1996). Graduate students' ownership and attribution rights in intellectual property. Indiana Law Journal, 71, 2, http://law.indiana.edu/ilj/volumes/v71/no2/patel.html. Accessed Marsh 20, 2010.

Pavela, G. (2005). Academic freedom for students has ancient roots. The Chronicle of Higher Education, 51(38), B8.

Robinson, S. (2005). Values, spirituality and higher education. In S. Robinson \& C. Katulushi (Eds.), Values in Higher Education (pp. 226-241). Glamorgan: Aureus and University of Leeds.

Russell, C. (1993). Academic Freedom. London: Routledge.

Sadler, D. (1989). Formative assessment and the design of instructional systems. Instructional Science, 18, 119-144.

Sen, A. (1999). Development as Freedom. Oxford: Oxford University Press.

Sursock, A., \& Smidt, H. (2010). Trends 2010: A decade of change in European Higher Education. Brussels: European University Association.

Trow, M. (1973). Problems in the transition from Elite to mass higher education. Berkeley, Cal: Carnegie Commission on Higher Education.

Twaddle, M. (1966). The Oxford and Cambridge admissions controversy of 1834. British Journal of Educational Studies, 14(3), 45-58.

UNESCO Institute of Statistics (UIS). (2008). Global Education Digest 2008. Montreal: UIS.

United Nations. (2009). The Universal Declaration of Human Rights. http://www.un.org/en/documents/ udhr/. Accessed May 20, 2010.

United Nations Educational, Scientific and Cultural Organisation (UNESCO). (2009). The State of Higher Education in the World Today. http://portal.unesco.org/en/ev.php-URL_ID=46028\&URL_DO=DO_ PRINTPAGE\&URL_SECTION=201.html. Accessed Marsh 8, 2010.

Weber, M. (1973a). The academic freedom of the universities (originally published in 1909). In E. Shils (ed. and trans.) Max Weber on Universities: The Power of the State and the Dignity of the Academic Calling in Imperial Germany (pp. 18-23), Chicago and London: University of Chicago Press.

Weber, M. (1973b). The Meaning of Ethical Neutrality in Sociology and Economics (originally published in 1917). In E. Shils (ed. and trans.) Max Weber on Universities: The Power of the State and the Dignity of the Academic Calling in Imperial Germany (pp. 47-54), Chicago and London: University of Chicago Press.

Welfare, L. E., \& Sackett, C. R. (2010). Authorship in student-faculty collaborative research: Perceptions of current and best practices. Journal of Academic Ethics, 8, 199-215. 